\title{
The treatment of shell-shock
}

\section{Cognitive therapy before its time ${ }^{\dagger}$}

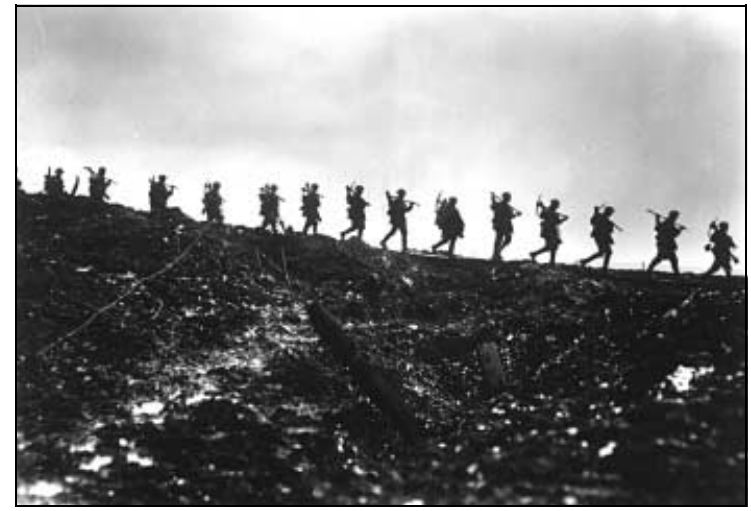

Figure 1. Working party of the Manchester Regiment on the Ancre, 1917. (Photograph Q1789 courtesy of the Imperial War Museum, London.)

\begin{abstract}
"I had a sister first, then a brother, then another brother - he was the one that was killed - and the next brother, who was also in the army, went out, and he got shell-shock. Of course, they didn't understand anything about it at all in those days. He was put on light duty at first, and for, I should think, two-and-ahalf years, we had the most terrible life with him. I don't mean because he could help it - he couldn't help it at all - and no doctor seemed to be able to do anything with him at all.

About five times a day, he'd say he was going to commit suicide. We knew he wouldn't, but he'd got to be watched, all the time, and he would wake up in the night, screaming - and my mother would go and sit with him - saying 'Oh, I can't go back to it'. . It was absolutely terrifying when he woke up, screaming and screaming and screaming." (Liddle Collection, Leeds University Library, further details available from author upon request)
\end{abstract}

This account, recorded at the age of 95 by the sister of a man who suffered from shell-shock, gives a vivid picture of the lasting disability endured by many victims, and the lack of understanding they faced when they returned to civilian life. However, the psychiatrists who specialised in treating the condition in fact attained a considerable degree of sophistication in both theory and treatment. Some of the methods they pioneered have more in common with present day cognitive approaches than with their avowed intent of pursuing Freudian psychoanalysis. I shall briefly describe the development of ideas about shell-shock with reference to contemporary currents in psychiatry, illustrating the parallels with more recent views about post-traumatic stress disorder (PTSD).

\section{Shell-shock and psychiatry}

Cases of shell-shock began to appear among the troops of the British Expeditionary Force late in 1914 during the retreat from Mons. The numbers affected continued to increase, and it quickly became a huge problem in all armies - in some areas nervous disorders accounted for $40 \%$ of the casualties. There was an epidemic rise from July to December 1916, during the Battle of the Somme, when 16000 cases were recorded in the British army alone (Merskey, 1979).

The experience of shell-shock was a major influence on the development of psychiatry and psychology. For one thing, it forced the realisation that otherwise normal people would break down under sufficient stress and so brought into question previous ideas of 'degeneration', popular in psychiatric thought at the time, which implied that there was a split between the healthily normal and the diseased portions of humanity.

The writings on neurosis in the First World War also continued the debate between physiological and psychological explanations of traumatic reactions, already familiar from the 19th-century controversy over 'railway spine'. Physiological explanations of mental disorder were in the ascendancy in the years before the First World War - partly because of psychiatrists' desire to be seen as legitimate members of the medical fraternity although this had begun to change with the increasing interest in psychological ideas. The War acted as a catalyst, consolidating the acceptance of purely psychological causes for mental symptoms. There were simply too many cases, many with no evidence of a physical trauma or of organic pathology, to support a physiological aetiology in any but a small number of them.

A third significant influence on the development of psychological medicine brought about by the First World War was the scope it gave for the practice of psychotherapy. Before the War there was certainly interest in this country in Freudian ideas, but few actually used psychological methods to treat neurotic disorders. There was strong opposition from the psychiatric establishment, particularly to the Freudian emphasis on sexuality as underlying mental disorder. British psychiatrists who were influenced by Freud were relieved to be able to use their experience with war casualties to show that sexual conflict was not fundamental to many cases of neurosis (Rivers, 1917).

\section{The nature of shell-shock}

Symptoms could generally be classed into two groups neurasthenic (which would nowadays be considered to be anxiety disorders) and hysterical reactions. The former were thought to be more likely to affect officers, while 
the latter were more common among private soldiers (Johnson \& Rows, 1923).

Many writers (such as W. H. R. Rivers) emphasised

special articles

the importance of helplessness and lack of control in leading to symptoms. Trench warfare was therefore particularly conducive to shell-shock since it involved long periods of inactivity in conditions of constant fear, with no opportunity for purposive action.

The eventual official recognition of war neurosis resolved a difficult dilemma for the military authorities. It enabled the removal of men from the sphere of disciplinary action and into the medical domain. The debate over cowardice and malingering was not made any easier, however, and there were violent differences of opinion about the status of psychological disorders in both the military and the medical worlds. This is demonstrated in the wide variety of opinions expressed by witnesses to the Southborough Committee, which was set up after the war to investigate the question of war neurosis (War Office Committee of Enquiry, 1922).

Overall management of nervous disorders was, however, facilitated by their official recognition. A system of clearing stations near to the front line was set up (based on the French hôpitals de triage), with only those men who failed to recover within two weeks being sent back to England. Medical services at home were quickly adapted to deal with the more serious cases needing prolonged and specialised treatment. By June 1918 there was a network of special hospitals throughout the British Isles, six for officers and 16 for other ranks. Patients were transferred after an initial reception at one of the clearing hospitals. Two training centres were set up, at Maghull, under R. G. Rows, and at the Royal Victoria Hospital, Netley, under C. Stanford Read. Both men were experienced psychiatrists with a particular interest in psychoanalytic ideas. Under them, groups of Royal Army Medical Corps doctors were given three-month courses on psychotherapeutic techniques of 'abreaction', with the emphasis on brief interventions designed to promote reexperiencing of the repressed memories and emotions of front-line experience.

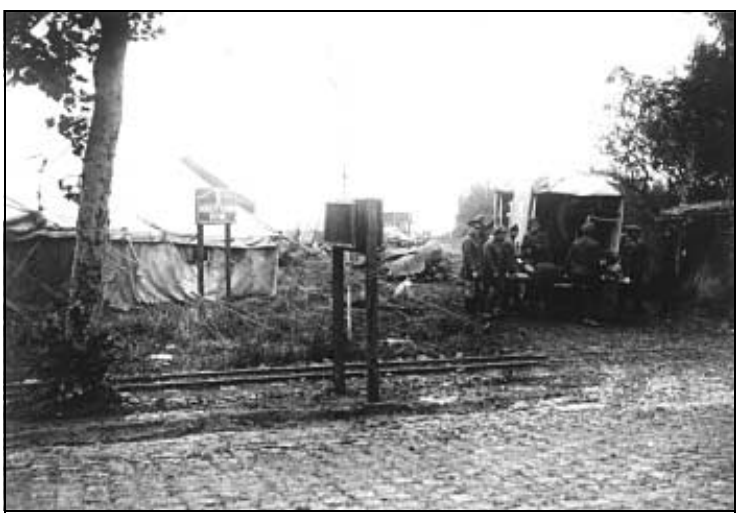

Figure 2. No. 13 Casualty Clearing Station. Wilfred Owen was treated here for shell-shock in 1917 by Dr William Brown before his transfer to Craiglockhart. (Photograph Q10418 courtesy of the Imperial War Museum, London.)

\section{Individual treatments}

Eric Leed, in his classic study of the effect of the First World War on individual character (Leed, 1979), has classified treatments as disciplinary or analytical in orientation. Disciplinary treatments, such as Lewis Yealland's (familiar from the novel and film of Regeneration (Barker, 1991)) highlighted the conflict between public duty and private intentions, therapy often becoming a battle of wills. The methods used were behavioural - electric shocks, shouted commands, isolation and restricted diet. Therapists using this approach had little time for psychological explanations for symptoms or of their meaning to the individual patient. The crucial factor was the patient's faith in the doctor, who had to instil the certainty of cure and did not give up until this was achieved.

More psychotherapeutically oriented therapists disavowed such purely symptomatic treatments. They considered neurosis to be a sign of unconscious conflict, the key to an internal drama leading back to the traumatic events of war. It was therefore necessary to uncover the trauma itself through such means as hypnosis, abreaction and other cathartic methods. In this way the patient could be helped to address his repressed memories and painful emotions, to come to terms with them and to reintegrate them into his personality. Unlike Freudian analysis, however, treatments were designed to be brief and were focused on recent traumatic events rather than on childhood experiences.

\section{Shell-shock and PTSD}

Important practitioners working along psychotherapeutic lines included Rivers, William McDougall, Charles Myers and William Brown, all of whom later became well-known in the field of academic psychology. Their principles of treatment are very similar to current ideas about how post-traumatic problems should be tackled.

(a) Prompt treatment (preferably close to the front line).

(b) The necessity to re-experience and /or go over the events (i.e. to acknowledge them, bring them into awareness)

(c) An emphasis on the meaning to the individual based on an individual psychological analysis.

(d) The use of cognitive restructuring (see particularly Rivers's (1918a) own examples in The Repression of War Experience).

(e) A collaborative approach between therapist and patient (the importance of a therapeutic alliance).

(f) The importance of previous experience in determining whether and in what way a person might break down.

Much work in PTSD has been in the area of cognitive psychology, and it is here that people such as Rivers can be seen to have been true precursors. There are various cognitive models of PTSD, broadly similar in their key themes. One model that is particularly helpful in making sense of the First World War experience is that of JanoffBulman \& Frieze (1983). They propose that problems arise because a person's "cognitive baggage" - his or her expectations about the world as meaningful, predictable 
and generally non-threatening - are called into question by the traumatic event. Three assumptions are shattered - the belief in personal invulnerability, the perception of the world as meaningful and comprehensible and the view of oneself in a positive light. Victims are continually afraid of a recurrence, see themselves as weak and vulnerable, and question whether there is any meaning to the world. Symptoms such as intrusive memories represent attempts to fit traumatic experiences into their previous conceptual framework.

The First World War was particularly destructive of previous structures of meaning. Although the men who fought were initially bolstered up by notions of King, Country, God or the greater good, these ideas became less and less sustainable as the war dragged on. Sassoon and Owen, as well as countless others, came to see the war as ultimately senseless. They returned to France out of a sense of fellow-feeling with their men, to share in their experiences and bear witness on their behalf. Owen wrote to his mother in October 1918: "I came here to help these boys - directly by leading them as well as an officer can; indirectly, by watching their sufferings that I may speak of them as well as a pleader can" (Owen, 1967). Sassoon's poem Sick Leave expresses similar sentiments (Sassoon, 1983). They despised the warmongers at home more than they hated the Germans, and felt alienated from the civilian world. Men who had lived through the horrors of the trenches found it impossible to communicate their experiences to those who had not: hence the silence of so many soldiers about the reality of the war. This silence must have contributed to the delayed cases of shell-shock following the War, as well as to conditions which might have been treatable given a greater awareness of the importance of prompt intervention.

Matters were made worse by the sense of helplessness engendered. Janoff-Bulman \& Frieze (1983) describe how post-traumatic symptoms can be modified if the sufferer feels that he or she can gain more control over the situation, and thereby foster the belief that he or she can guard against future traumatisation through his or her own efforts. But conditions in the trenches did not allow such adaptation. The mechanistic, deskilled nature of the soldier's role, dominated as it was by machinery and bureaucratic routine, has often been pointed out. He was reduced to the most basic level of functioning, and had it drummed in that his life was no more than a figure in a vast game of numbers being played by men in authority whom he never saw. Rivers (1918b) described the way in which military training emphasised the repetition of simple tasks until they become automatic. This routine reinforced the men's sense of helplessness, since any purposeful activity on their part was forbidden by the rules of the military game.

Despite their explicit debt to Freud, Rivers and his colleagues were closer in both theory and practice to cognitive psychology than to psychoanalysis. Early treatment, an integral part of present day disaster management, was a central feature of the remarkably comprehensive system brought in towards the end of the First World War, when it was recognised that it could help to prevent later disability.

special articles

\section{Comment}

The shell-shock experience helped to break down the distinction between the sane and the insane. It became clear that, given sufficiently extreme circumstances, anyone could break down. It also helped increase the scope of psychiatry through its involvement with questions of military discipline and human responsibility. This led directly to a change in the law relating to military insubordination, and in 1930 the new Labour government removed the death penalty for desertion and cowardice.

Ideas about mental illness changed greatly as a result of the War. Theories invoking physiological mechanisms such as heredity and degeneration were eclipsed by psychological explanations, and there was an upsurge in the popularity of psychotherapeutic methods. It perhaps encouraged psychiatrists to listen more closely to what their patients had to tell. The legacy of thousands of shell-shocked soldiers also contributed to institutional changes such as the growth of the out-patient clinic and voluntary treatment in mental hospitals.

Above all, acquaintance with the neuroses of war combined with other currents in early 20th century experience to create the modern world: one familiar with Freudian ideas, in which psychiatry, psychology and talking therapies are called upon to explain, take responsibility for, and treat, ever wider areas of human life.

\section{Acknowledgement}

I thank Dr Alan Kerr for his help in preparing and editing this paper.

\section{References}

BARKER, P. (1991) Regneration. London: Viking.

JANOFF-BULMAN, R. \& FRIEZE, I. H. (1983) A theoretical perspective for understanding reactions to victimisation. Journal of Social Issues, 39, 1-17.

JOHNSON, W. \& ROWS, R. G. (1923) Neurasthenia and war neuroses. In History of the Great War Medical Services: Diseases of the War, vol. 2. London: HMSO.

LEED, E. (1979) No Man's Land. Cambridge: Cambridge University Press.

MERSKEY, H. (1979) The Analysis of Hysteria. London: Gaskell.

OWEN,W. (1967) Collected Letters (eds H. Owen \& J. Bell). Oxford: Oxford University Press.

Peter W. Howorth Specialist Registrar in Psychiatry, Whitecliff Centre, East Cleveland Hospital, BrottonTS12 2XT
RIVERS, W. H. R. (1917) Freud's psychology of the unconscious. Lancet i, 912-914.

— (1918a) An address on the repression of war experience. Lancet, i, 173-177.

- (1918b) War neurosis and military training. Mental Hygiene, 2, 513-533.

SASSOON, S. (1983) The War Poems. London: Faber \& Faber.

WAR OFFICE COMMITTEE OF ENQUIRY INTO SHEL SHOCK (1922) Report of the Committee. London: HMSO.

Also archive material from the Liddle Collection of First World War material held at Leeds University and from the Public Record Office. 